\title{
PENERAPAN PEMROSESAN PARALEL UNTUK MENGUJI WAKTU RENDERING DESIGN WEB DENGAN FRAMEWORK TERHADAP PROCESSOR MELALUI LAN, ROUTER DAN EKSTRANET
}

\author{
Ngadiyono, Hero Wintolo \\ Program Studi Teknik Informatika \\ Sekolah Tinggi Teknologi Adisutjipto Yogyakarta \\ informatika@.stta.ac.id
}

\begin{abstract}
Designing a website is the first step to buildwebsite that gives the appearance of an interface to the website visitor. the appearance web design that interesting can begivedconveniences for visitors to browse the contents of any website content. designing of the website, skill are required several to be master multiple web programming languages, the programming language are HTML, CSS and Javascript.In the overall control of the programming language takes time to be master and understand each other codes. Therefore, to built application that allows users to create a website design. This application is called WebEditor is built using CodeIgniterand Twitter Bootstrap framework. In the rendering process design needed parallel processing techniques to the process. so, the impact in terms of rendering time speed to website design. Throughout this system, users can design a website easily and quickly, and in the process of rendering design does not require for long time. the results of study case have done that it can be seen that influences of the implementation of rendering speed transmission media based on the number of processors and computers server. The percentage of the speed to rendering of design does not using a grid server on the LAN network are $33.7 \%, 33.3 \%$ and internet routers $33 \%$. While using a part of grid servers on the LAN network are $33.6 \%, 33.4 \%$ and internet routers $33 \%$ and the final grid using 2 servers on the LAN network are $44 \%, 33 \%$ and internet routers $26 \%$. So the highest rendering speed on the LAN routernetwork for further $44 \%$ and $30 \%$ at the latest on the Internet $26 \%$ by using 2 part of grid servers. Thus rendering the best in the website design is using LAN with 2 part of grid servers.
\end{abstract}

Keywords : website design, LAN, routers, internet, parallel processing.

\section{Pendahuluan}

Pemrosesan parallel merupakan salah satu bidang dalam ilmu computer atau teknik informatika yang mengkaji tentang eksekusi sebuah proses atau job dengan jumlah yang banyak. Jumlah proses yang banyak tidak dapat dikerjakan oleh sebuah komputer yang memiliki prosesor tunggal, jika dipaksakan akan membuat waktu menyelesaikan proses menjadi lama. Sehingga dibutuhkan banyak prosesor untuk mempersingkat waktu proses dengan menggunakan pemrosesan paralel. Salah satu proses yang dapat diselesaikan secara parallel yaitu rendering desain website. Sekarang perkembangan desain website mengalami peningkatan yang sangat cepat. Salah satunya perkembangan framework desain website yang berfungsi untuk memudahkan pembuatan website secara cepat dengan berbagai komponen elemen website pendukungnya.

\section{Kajian Pustaka}

Jurnal ilmiah ini dibuat oleh Hero Wintolo, S.T., M.Kom, Yuliani Indrianingsih, S.T., M.Kom, Ika Kartika Sari, S.Kom. Di sini diterangkan bahwa Grid Computing merupakan kumpulan komputer yang saling berhubungan dan saling bekerjasama untuk menyelesaikan pekerjaan tertentu. Komputer komputer grid tersebut harus koheren agar prosesor dapat bekerja secara seimbang saat mendapat 
pekerjaan dari server. Grid Computing dapat dimanfaatkan dalam banyak hal, dan dalam penelitian ini akan digunakan dalam proses kompilasi kode program $\mathrm{C} / \mathrm{C}++$.

Proses kompilasi merupakan proses mengubah kode program yang dipahami manusia menjadi kode program yang mudah dipahami komputer. Proses kompilasi dilakukan oleh sebuah compiler yang terpasang pada sebuah Personal Computer (PC). Pemanfaatan grid pada proses kompilasi akan mengurangi waktu tunggu antrian kode program yang akan dikompilasi kode program $\mathrm{C} / \mathrm{C}++$ dengan memanfaatkan teknologi grid computing didalamnya. Pekerjaan yang datang akan dibagi-bagi kepada komputer-komputer grid yang tidak sedang mengerjakan pekerjaan. Pemanfaatan grid computing pada proses kompilasi juga akan membantu seseorang yang tidak mempunyai compiler $\mathrm{C} / \mathrm{C}++$ pada $\mathrm{PC}-\mathrm{nya}$.

\section{MetodePenelitian}

\subsection{Metode pengumpulan data}

Metode kepustakaan adalah suatu metode pengumpulan data melalui buku-buku literatur ataupun dokumen yang berhubungan dengan metode pemrosesan paralel.

\subsection{Perancangan perangkat lunak}

Perancangan aplikasi menggunakan konsep OOP (Object Oriented Programming) yaitu suatu metode perancangan program yang berorientasi pada objek.

\subsubsection{Analisis Sistem}

Pemanfaatan website di jaman sekarang sangat beragam fungsinya, baik itu berupa sarana media sosial, sarana informasi atau sebagai proses transaksi secara online. Tetapi ada kendala di dalam pembuatan website khususnya pembuatan desain website yang tidak dapat diketahui secara umum, sehingga banyak tercipta sebuah alat yang digunakan sebagai perancangan desain website baik secara online maupun secara offline.

\subsubsection{Perancangan Paralel Sistem}

Di dalam proses rendering website terdapat proses yang terbagi dan dikerjakan oleh grid server yang membantu proses dari server utama dan tugas server utama melakukan pembagian sebuah job pekerjaan yang di request dari user dan dikerjakan grid server yang sedang tidak ada proses yang dilakukan selanjutnya hasilnya dikembalikan ke server utama dan menjadi response bagi. Proses parallel dapat dilihat pada Gambar 1 . 


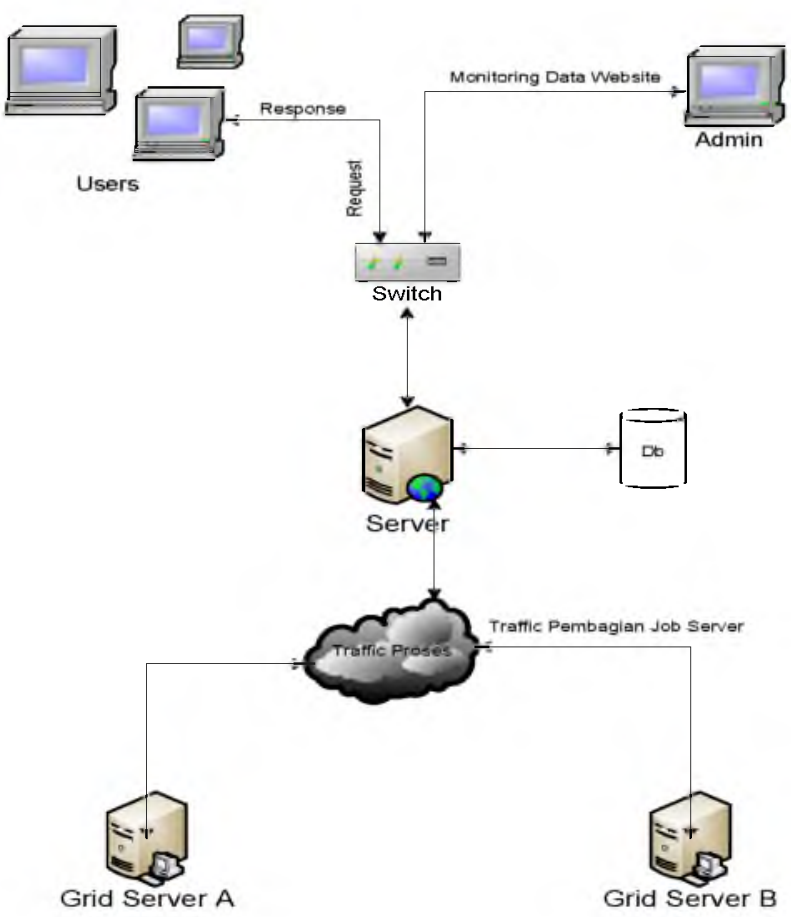

Gambar 1 Proses Paralel Sistem

\section{Hasil dan Pembahasan}

Uji Fungsi merupakan tahapan selanjutnya dari penelitian ini, uji fungsi berupa uji tingkat perbandingan kecepatan rendering desain website berdasarkan ukuran besar memori desain dan jumlah komputer yang menjadi grid server.

\subsection{Uji Fungsi Web Editor Dengan LAN}

Pengujian rendering desain website dengan LAN merupakan pengujian aplikasi di dalam jaringan local dengan memanfaatkan media transmisi kabel LAN danswitch. Pengujian pada penelitian ini menggunakan 4 komputer yang sudah diberi alamat IP agar setiap computer dapat saling terhubung. Satu buah computer dijadikan server utama dan 1 buah computer lagi dijadikan sebagai pihak client. Dua buah computer dijadikan grid server yang tugasnya membantu pekerjaan server utama Setelah masing-masing computer diberi alamat IP, 4 komputer tersebut dihubungkan ke switch dengan menggunakan kabel RJ45 (LAN).

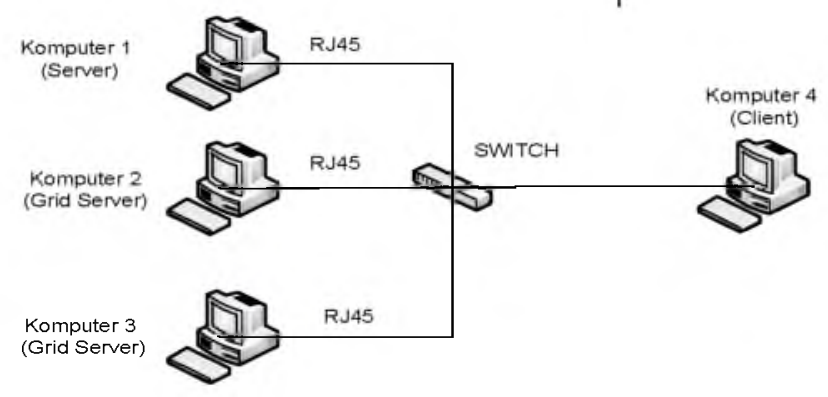

Gambar 2. Skema Uji CobaWeb Editor Dengan LAN

\subsection{Uji Fungsi Web editor Menggunakan Router (Network Berbeda)}

Uji fungsi selanjutnya dilakukan pada Web Editor dengan alamat IP network yang berbeda menggunakan sebuah router. Pengujian ini dilakukan untuk melihat kemampuan aplikasi dalam melakukan komunikasi antar computer dalam jaringan local dan dengan subnet yang berbeda.Tempat 
pengujian dilakukan di laboratorium jaringan STTA dengan menggunakan 4 komputer, 1 switch dan 2 buah router CISCO.



\subsection{Uji Fungsi Web editor Menggunakan Jaringan Internet}

Tahapan dalam melakukan uji coba selanjutnya adalah dengan internet. Uji coba Web Editor menggunakan jaringan internet merupakan uji coba aplikasi di dalam jaringan internet dengan menggunakan modem GSM.

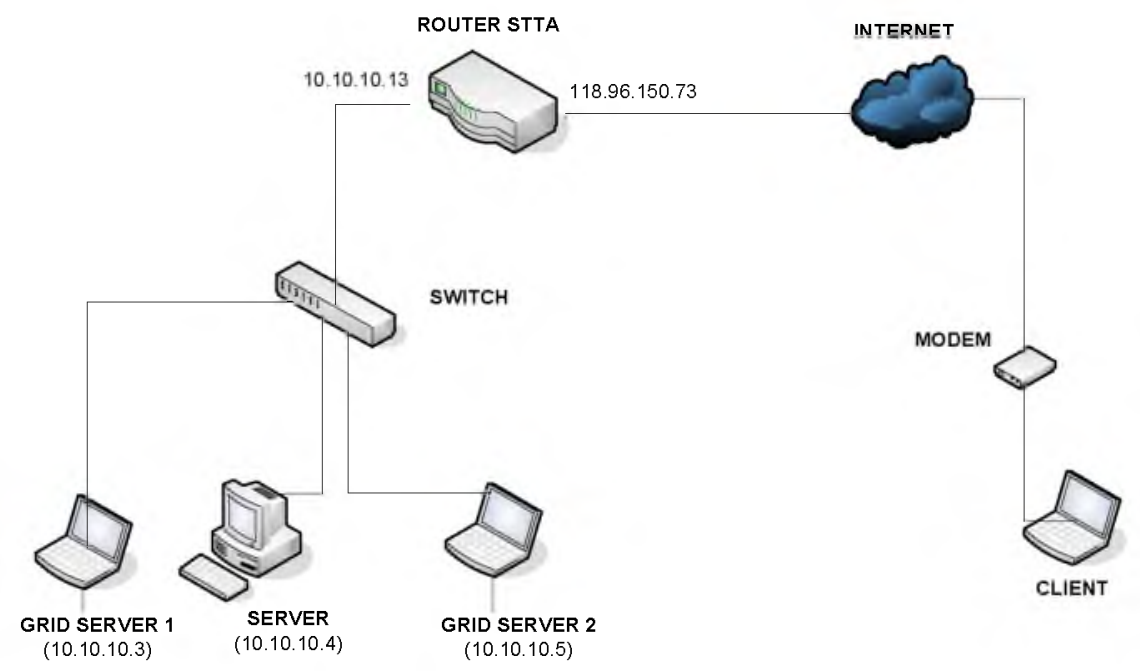

Gambar4. Skema Uji Coba Web Editor Pada Jaringan Internet

\subsection{Analisa Hasil Uji Fungsi}

Dari pengujian proses rendering desain website yang dilakukan menggunakan 3 jenis jaringan yaitu jaringan LAN, jaringan menggunakan router CISCO dan jaringan internet diharapkandapat membuktikan availabilitas aplikasi yang mampu diterapkan di berbagai jenis jaringan computer dengan kecepatan yang berbeda. Diperoleh analisa dari hasil uji coba tersebut. Berdasarkan data yang diperoleh dari 3 pengujianya itu pengujian menggunakan jaringan LAN, menggunakan router dan menggunakan jaringan internet dapat terlihat perbandingan rata-rata kecepatan dari 3 pengujian tersebut dapat dilihat pada Tabel 1. 
Tabel 1 Hasil Pengujian Kecepatan Rata-Rata BerdasarkanTipeJaringan

\begin{tabular}{|c|c|c|c|c|}
\hline TransmisiJaringan & $\begin{array}{c}\text { Rata-rata } \\
\text { UkuranDesain } \\
\text { (Bytes) }\end{array}$ & $\begin{array}{c}\text { Rata-Rata Grid } \\
\text { Server 0 }\end{array}$ & $\begin{array}{c}\text { Rata- } \\
\text { Rata-Rata Grid } \\
\text { Server 1 }\end{array}$ & $\begin{array}{c}\text { Rata } \\
\text { Grid } \\
\text { Server } \\
2\end{array}$ \\
\hline LAN & 123,921 & 2,03344 & 1,03232 & 0,02828 \\
\hline Router & 123,921 & 2,03629 & 1,03544 & 0,03215 \\
\hline Internet & 123,921 & 2,04752 & 1,05679 & 0,04792 \\
\hline
\end{tabular}

Berdasarkan analisa padaTabel ldapat diambil persentase kecepatan rendering desain antar ketiga tipe jaringanya itu jaringan LAN, jaringan router dan jaringan internet. Ukuran desain yang diambil adalah rata-rata dari semua pengujian aplikasi sebanyak 10 buah pengujian tidak menggunakan grid server yaitu didapat nilai 123,921 bytes.



Hasil persentase kecepatan dari jaringan LAN adalah 33,6\% dari 2,03344 detik rata-rata kecepatan rendering desain. Sedangkan hasil persentase kecepatan dari jaringan router adalah 33,4\% dari 2,03629 detik rata-rata kecepatan rendering desain dan yang terakhir hasil persentase kecepatan dari jaringan internet adalah $33 \%$ dari 2,04752 detik rata-rata kecepatan rendering desain.

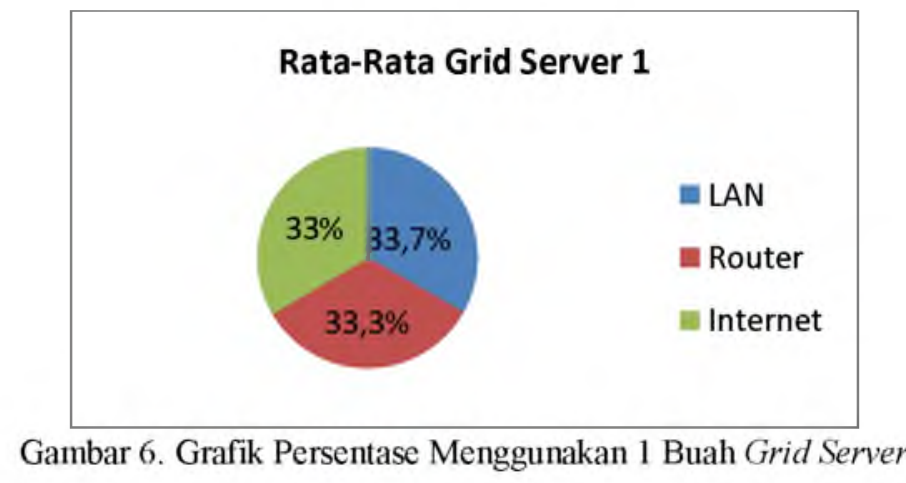

Pada jaringan LAN mempunyai nilai persentase $33,7 \%$ dari 1,03232 detik rata-rata kecepatan rendering desain sedangkan pada jaringan router mempunyai nilai persentase $33,3 \%$ dari 1,03544 detik rata-rata kecepatan rendering desain dan pada jaringan internet mempunyai nilai persentase $33 \%$ dari 1,05679 detik rata-rata kecepatan rendering desain. 


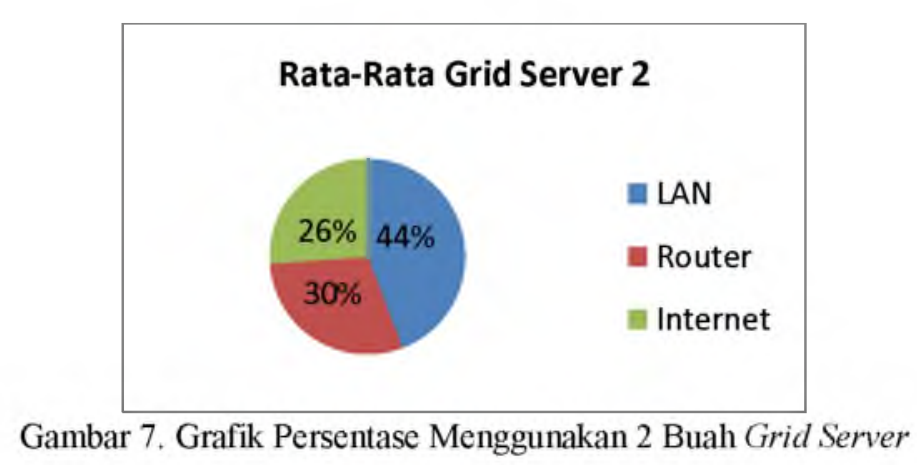

Pada jaringan LAN mempunyai nilai persentase $44 \%$ dari 0,02828 detik rata-rata kecepatan rendering desain sedangkan pada jaringan router mempunyai nilai persentase $30 \%$ dari 0,03215 detik rata-rata kecepatan rendering desain dan pada jaringan internet mempunyai nilai persentase $26 \%$ dari 0,04792 detik rata-rata kecepatan rendering desain.

\section{Penutup}

\subsection{Kesimpulan}

1. Rendering desain website dapat menggunakan pemrosesan parallel dengan meletakan dua computer sebagai pemroses dan satu buah computer pembagi job yang akan diproses. Komputer dengan 2 buah grid server memberikan pengaruh kecepatan tertinggi pada setiap rendering desain website.

2. Jumlah processor dan kecepatan setiap processor menjadi faktor penentu cepat atau tidaknya sebuah proses yang dikerjakan olehkomputer yang mengerjakan proses. Jumlah processor pada aplikasi Web Editor berjumlah 3 dan kecepatan setiap processor 2,27 Ghz. Proses tercepat rendering desain menggunakan 2 buah grid server dengan persentase pada jaringan LAN 44\% dari 0,02828 detik, jaringan router 30\% dari 0,03215 detik dan jaringan internet $26 \%$ dari 0,04792 detik.

3. Tool framework Twitter Bootstrap berupa kumpulan element website yang cocok untuk diterapkan pada editor desain website sebagai tool desain.

\subsection{Saran}

1. Sistem dikembangkan tidak hanya bersifat aplikasi web saja tetapi juga dapat dibuat versi desktop dan versi mobile agar dapat lebih informative dan useful di dalam penggunaannya.

2. Tool desain dapat mengalami penambahan tidak hanya dari framework Twitter Bootstrap tetapi bisa ditambahkan framework desain yang lainnya.

\section{DaftarPustaka}

Clement, S., Pottle, B., and Singh, 2010, Oracle Database : SQL Fundamental I, Oracle, Edition 1.0.

Jogiyanto, 2005, Analisis \& Desain, Sistem Informasi : Pendekatan Terstruktur Teori Dan Praktik Aplikasi Bisnis, ANDI OFFSET, Edisi III.

Raharjo, Budi, 2011, Belajar Otodidak Pemrograman Web Dengan PHP + Oracle, Informatika.

Wagito, 2005, Jaringan Komputer Teori dan Implementasi Berbasis Linux. Gavamedia.

Wilikison, Barry dan Allen, Michael, 2010, Parallel Programing, Andi Offset.

Wintolo, H., Indrianingsih, Y., dan Kartika Sari, I., 2013, Penerapan Grid Computing Untuk Mengkompilasi Program Berbahasa $\mathrm{C} / \mathrm{C}++$, Jurnal Proceding Seminar Nasional Teknologi Informasi Dan Kedirgantaraan, ISSN 2337-3881. 